\title{
CONTEXTUALIZACIÓN HISTÓRICA DE ALGUNOS TEXTOS LITERARIOS PUBLICADOS EN LA REVISTA MEXICANA DECIMONÓNICA EL AÑO NUEVO. PRESENTE AMISTOSO, EN TORNO AL TÓPICO DEL PAISAJE COMO ELEMENTO DE IDENTIDAD NACIONAL
}

Historical contextualization of some literary writings about the landscape as an element of national identity published in the nineteenth-century magazine El Año Nuevo. Presente Amistoso

María Margarita Alegría de la Colina ${ }^{1}$

Fecha de recepción: 10 de octubre del 2018

Fecha de aceptación: 20 de abril del 2019

1- Nacionalidad: Mexicana. Grado: Doctorado. Especialización: Literatura. Adscripción: Universidad Autónoma Metropolitana Unidad Azcapotzalco. Correo electrónico: alegria_margo@yahoo.com.mx. DORCID: http://orcid.org/0000-00032241-707X 


\section{Resumen}

En el contexto de la situación socio-política mexicana al iniciar el siglo XIX y de la manera en que la nación fue sentando sus bases en ciertos paradigmas de identidad, en este texto se revisa el tópico del paisaje tanto natural como urbano a través de algunos poemas y relatos aparecidos en la revista El año nuevo. Presente amistoso, de la que se publicaron cuatro volúmenes entre 1837 y 1840.

Palabras clave: Siglo XIX mexicano, contexto histórico-cultural, identidad, paisaje, poemas, relatos.

\section{Abstract}

Within the context of early XIX century Mexico, its socio-political situation, and the way its nation started settling its foundations based on certain identity paradigms, this text explores the topic of natural and urban landscape through poems and tales printed in El año nuevo. Presente amistoso, a magazine of which four issues were published between 1837 and 1840.

Keywords: XIX century Mexico, historical and cultural context, identity, landscape, poems, tales. 


\section{Introducción}

En el siglo XIX mexicano se estaba conformando una nueva nación y en ese esfuerzo los escritores jugaron un importante papel, Jorge Ruedas de la Serna menciona en su "Presentación" al libro La misión del escritor. Ensayos mexicanos del siglo XIX, que "quienes ejercieron el oficio de escritor contribuyeron a darle a la literatura una especial dimensión entre las actividades humanas, "mayormente resaltando su utilidad y su importancia para mejorar a la sociedad, depurar sus costumbres, robustecer la moral pública, revalorar nuestro patrimonio geográfico y cultural, afirmar nuestra identidad y, con todo ello, fortalecer la conciencia nacional.”( 1996: 7-8), dedicaron así su arte a la tarea de formación del nuevo país.

Ignacio Manuel Altamirano declaró en su primera revista literaria (1868) publicada en el tomo I de su libro La literatura nacional: " si algo es rico en elementos para el literato, es este país, del mismo modo que lo es para el agricultor y para el industrial.” (1949: 10) y refiriéndose particularmente al paisaje señaló:

¿Quién al ver los risueños lagos del Valle de México, sus volcanes poblados de fantasmas, cuyas leyendas recogen los habitantes de la falda, sus pueblos fértiles, sus encantados jardines y sus bloques seculares, por donde parecen pasearse aún las sombras de los antiguos sultanes del Anáhuac y las de sus bellas odaliscas princesas, no se ve tentado a crear la leyenda mexicana? (1996: 12).

Hacer referencia al paisaje nacional, a la feracidad de su tierra, a los imponentes volcanes, a sus lagos y ríos y, con énfasis en el carácter civilizado del país, a sus espacios urbanos: edificios, parques y monumentos fueron, entonces, sendos motivos en la poesía, la narrativa o el cuadro de costumbres.

En el contexto de la búsqueda de una identidad que no acababa de perfilarse, se vio aumentar la producción literaria a través de periódicos y revistas y en el seno de las asociaciones respectivas. En los mismos años que se publicó la revista El año nuevo. Presente amistoso, de cuyas páginas he elegido algunos textos para resaltar la importancia de los paisajes a que hacen referencia, en relación con los temas que se destacaban precisamente para fortalecer la identidad nacional, nacieron también, entre otras revistas: El mosaico mexicano (1836-1837, 1840-1842), El recreo de las familias (1838), El museo mexicano (18431846), El Liceo mexicano (1844) y se editaba periódicos como El Zurriago (1839-1840, 1843-1844) o El Siglo diez y nueve (1841-1858), en dichas publicaciones los escritores contribuían con poemas, relatos o artículos diversos algunas veces traducidos del inglés o del francés.

El año nuevo. Presente amistoso, fue el órgano de difusión de la Academia de Letrán, asociación literaria a la que me referiré más adelante, cuyo mérito principal fue el empeño de sus integrantes por nacionalizar la literatura mexicana. A Ignacio Rodríguez Galván, uno de los integrantes de aquel grupo, “ se le ocurrió [apunta Fernando Tola de Habich] la feliz idea de los Año Nuevo [... los textos allí publicados] figuraban [señala más adelante dicho autor] como aportes modestos, de escritores modestos, que lo único que deseaban era que los lectores se identificaran con los sentimientos expresados por -eso sí- escritores mexicanos" (1996: XXXV-XXXVI). Si la calidad literaria de muchos de los textos publicados en esas revistas oscila en la medianía, hay algunos de méritos muy relevantes. Pero no es el objetivo de este artículo presentar un análisis de las cualidades literarias de los textos publicados en El año nuevo...; sino 
ejemplificar con la contextualización histórica de algunos de ellos, la importancia del paisaje como elemento destacado en la construcción de la identidad nacional, cuando México se estrenaba como nación.

Los estudio sobre el paisaje que se realizan hoy en día consideran los aspectos sociales, identitarios y culturales, en general, que con él se relacionan. Florencio Zoido Naranjo cita a Testuro Watsuji quien señala que "La historicidad no es la única estructura de la vida humana social. También lo es, inseparablemente, la ambientalidad. En la unión de ambientalidad e historicidad toma cuerpo, por así decirlo, la historia humana. Geografía e historia, paisaje y cultura son inseparables" (2012). En este sentido, la reflexión que llevo a cabo en este artículo, como producto del análisis de textos literarios del siglo XIX mexicano, pretende vincular justamente dichos rasgos.

No trataré aquí del paisaje como el "género del yo" al que se refiere Juan Pascual Gay (2009). Mi interés es vincular el tratamiento que algunos colaboradores de El año nuevo... hacen de este, con las situaciones históricas que le confieren importancia, o con los valores naturales que lo llevan a ser considerado como emblemático,, es el caso de "El Nevado de Toluca", por ejemplo.

Como ha señalado Nicolás Ortega Cantero, desde comienzos del siglo XIX "se empezó a ver en el paisaje, entendido al principio en términos marcadamente naturalistas, una expresión real y simbólica de los pueblos y de las naciones" (2005: 9), dicho autor se refiere al caso específico de España, pero reconoce que el romanticismo vio nacer el primer paisajismo geográfico moderno, en virtud del cual acercarse a las cualidades y valores del paisaje para comprender lo que este es y significa, puede ser un camino para formar conciencia histórica y conciencia nacional.

Esta visión del paisaje, herencia en México de las ideas de Alexander von Humbolt ,considera como parte del mismo al ser humano, cuyas acciones, relaciones y combinaciones lo atraviesan. Resumiendo dicha visión, Ortega Cantero apunta que "el paisaje es un testimonio y un símbolo de la vida de los hombres que lo habitan y de la identidad colectiva, nacional, que han conformado a lo largo de esa historia." (2005: 10).

El análisis que aquí presento es producto de una investigación que vincula precisamente lo geográfico, lo histórico y lo identitario; además, como dice Maderuelo, para existir, el paisaje requiere de alguien que pueda leer e interpretar ese "algo". Es dentro de esta relación que el concepto de "paisaje" adquiere sentido. Una relación en la cual el individuo (alguien) es capaz de percibir lo que yace (algo) e interpretarlo" (2005: 25). Los obras de los escritores a cuyos textos hago referencia más adelante resultaron de la interpretación literaria de los paisajes que ellos observaron: Como lectora de sus textos, quien esto escribe realiza también un trabajo interpretativo, que ciertamente no responde solo a una apreciación subjetiva, precisamente por la investigación histórica con base en la cual se refuerza el planteamiento de que las referencias al paisaje por parte de dichos autores, miembros de la Academia de Letrán que publicaron en El año nuevo..., tenían una intención consciente de contribuir a la conformación de la identidad nacional, evidenciarlo en estas páginas es mi propósito, razón por la cual no me detengo en analizar a fondo los valores estético.-literarios de los textos. Ubico primero el momento histórico de la producción de los mismos, tanto desde el punto de vista social como desde el literario, y si llevo acabo un análisis es en términos de contextualizar geográfica e históricamente, el paisaje al que cada poema o relato hace referencia. 


\section{Situación histórica}

La segunda mitad del siglo XVIII fue una época de auge económico en Nueva España. Luis Villoro consigna que mientras las rentas totales de esta colonia se contaban en tres millones de pesos hacia 1712, ascendieron a 21 para 1808. A esa prosperidad, apunta Villoro, correspondía un florecimiento cultural que trajo consigo el arte churrigueresco novohispano seguido de la revolución neoclásica. Hubo desarrollo en las ciencias en torno a la Escuela de Minería; en fin, señala dicho autor, "espiritual y materialmente, la sociedad de la Nueva España alcanza su más alto grado de esplendor en aquella época” (1999: 21). Fue así que los criollos, según Lucas Alamán: "[se] formaron un concepto extremadamente exagerado de la riqueza de su patria y se figuraron que ésta (sic), siendo independiente, vendría a ser la nación más poderosa del universo." (Villoro, 1999: 21).

Aunque ciertamente esa convicción no era compartida por todas las capas sociales. El que Villoro denomina "grupo europeo", formado por peninsulares, ocupaba todos los cargos de funcionarios y burócratas, así como del alto clero. Controlaba también el poder económico, ya que eran europeos la mayoría de los grandes comerciantes. Para ellos "la prosperidad material no indica ninguna posible transformación sino exige, tan solo, un orden administrativo eficaz." (Villoro, 1999: 25).

Los criollos eran los grandes hacendados. Había cerca de cinco mil haciendas cuya producción daba lugar al mercado nacional o regional; mientras los indígenas constituían una comunidad campesina de baja productividad, reducida al autoconsumo. Los primeros, no obstante, tenían capitales muy inferiores a los que producía la minería y estaban sujetos a las fluctuaciones cíclicas de los precios agrícolas, mal del que nunca pudo librarse la economía del virreinato (Villoro, 1999:25).

El clero, por su parte, además de recibir rentas por sus propiedades y diezmos, fungía como especie de banco, pues prestaba dinero a hacendados, industriales y pequeños comerciantes. Controlaba también mediante hipotecas muchas propiedades rurales; pero España era la dispensadora de las prebendas. Esta situación provocó que si bien "el principio del siglo XIX [fue] una época de optimismo; lo [fue] también, empero, de irritación y descontento."(Villoro, 1999:28).

Debido al relativo crecimiento del mercado interno, al incipiente desarrollo urbano industrial y al aumento de la burocracia, hubo un cierto crecimiento de los sectores intermedios: pequeños comerciantes y administradores, escribanos y abogados que junto con el personal eclesiástico de bajo rango integraban una clase media, no obstante, inconforme. Lo estaba también, con mayor razón, el sojuzgado pueblo trabajador del que formaban parte indios y castas. La revolución de independencia fue la respuesta a ese descontento social.

El acta de Independencia de 1821, inspirada en las ideas de los liberales que Agustín de Iturbide había incorporado a la Junta Provisional Gubernamental, señalaba: "La nación mexicana, que por trescientos años ni ha tenido vida propia, ni libre uso de la voz, sale hoy de la opresión en que ha vivido"(Villoro, 1999: 141).

En el México recién inaugurado, los intelectuales trabajaron por construir la imagen de una nación civilizada y próspera. Trataban de desterrar la "leyenda negra" sobre América y sus pobladores acuñada por europeos como el holandés De Paw (Cornelius de Paw. Investigaciones filosóficas sobre las Américas), el francés Buffon (Historia natural, general y particular) y el inglés Robertson, entre otros (Kohut, 2008: 
52-81). A lo largo del siglo XIX, en este país se reunían academias de todo tipo para la producción artística y el estudio científico.

El 18 de abril de 1833, se instauró la Sociedad Mexicana de Geografía y Estadística que tenía como antecedente el Real Seminario de Minería de la Nueva España, también llamado Colegio Metálico o de Minería fundado en 1792, que se ubicó primero en el número noventa de la actual calle de Guatemala y en 1811 cambió su sede al Palacio de Minería.

En el seno de dicha sociedad se elaboraron la primera Carta General de la República, el Atlas y el Portulano. Por iniciativa de dicha institución, el gobierno expidió leyes para determinar los nombres geográficos de ciudades y otros sitios de la República, y estableció la legislación para la protección de bosques y la conservación de monumentos arqueológicos, como propiedad nacional. (Rosas, 2012: 18-24).

Se fundó también en esa primera mitad del siglo la Academia de Medicina de México en 1836; y ya en 1825 se había publicado el decreto para la constitución del Museo Nacional Mexicano por el primer presidente del país, Guadalupe Victoria. Inicialmente se instaló en las salas de la universidad; posteriormente, el emperador Maximiliano, durante el Segundo Imperio, proporcionó un local especial en donde se inauguró bajo el nombre de Museo Nacional de Arqueología, Historia y Etnografía. En él se agruparon biólogos, historiadores, arqueólogos y lingüistas de la época. Derivado de los trabajos de dicha institución, a finales del siglo XIX se conocían unas cuantas zonas arqueológicas como Tajín, Teotihuacán, Mitla, Monte Albán, Isla de Sacrificios, Uxmal, Palenque y Xochicalco.

Ya en la segunda mitad de esa centuria, se organizaron otras asociaciones como la Sociedad Mexicana de Historia Natural en 1868 y, en 1891, el Instituto Geológico Nacional. En el seno del ya mencionado Museo Nacional de Arqueología, Historia y Etnografía, durante el Porfiriato, los científicos positivistas se dedicaron al conocimiento de las poblaciones indígenas, a la reconstrucción de una historia prehispánica "veraz" y a la definición del mexicano, contribuyendo así a la formación del sentimiento nacionalista.

Quizás las más numerosas fueron las asociaciones literarias. Alicia Perales (2000) hace mención de más de noventa a lo largo del siglo entre veladas, tertulias, sociedades, reuniones, liceos, institutos, clubes, círculos, centros, bohemias, ateneos, arcadias, agrupaciones y academias.

Entre todas ellas, en 1836 se fundó la que se propuso hacer una literatura auténticamente mexicana: la Academia de San Juan de Letrán. Esta asociación nació como una tertulia cuyo antecedente fueron las reuniones en casa del poeta Francisco Ortega. Dichas reuniones se siguieron llevando a cabo en la habitación de uno de los maestros del colegio de San Juan de Letrán, institución que funcionó durante toda la colonia y parte de la época independiente.

José María Lacunza era el maestro. Juan Nepomuceno, su hermano, Manuel Tossiat Ferrer y Guillermo Prieto, alumnos que lo acompañaron en esa aventura; después se fueron integrando nuevos miembros, dado que aquellas reuniones iban cobrando fama. Formaron parte de esa Academia Fernando Calderón, Ignacio Ramírez, Eulalio María Ortega, Joaquín Navarro y Antonio Larrañaga entre los liberales. Manuel Carpio y José Joaquín Pesado fueron los de tendencia conservadora. Andrés Quintana Roo, su presidente vitalicio.

Alicia Perales apunta que la Academia de Letrán tuvo propósitos nacionalistas bien definidos. Los escritores integrantes preferían lo nacional a lo extranjero y lo popular a lo aristocrático. Les preocupó la exaltación del pasado indígena y en su seno se llevaron a cabo los primeros intentos románticos alentados por el poeta cubano radicado en México, José María Heredia. (Perales, 2000: 74-81). 
Era el momento de lo que se ha considerado como primer romanticismo mexicano, en realidad, primer movimiento literario en la vida independiente de México. Según Celia Miranda Cárabes, dicho movimiento:

Ha sido caracterizado por la presencia de los elementos religioso y liberal, alusivo a la naturaleza, en conjunción con el sentimiento egocéntrico expresado en un fuerte individualismo, y en lo sobrenatural, apoyado en las ideas medievales. Lo caracterizan también la contraposición entre sentimiento y razón, audacia y mesura, rebeldía para proyectar en ellos un yo dolido por el tedio y la desesperanza de una soledad indefinible. (1985:17).

Más destacables me parecen, para los efectos del texto que aquí presento, las reflexiones que Isaiah Berlin hace al respecto, al considerar que este movimiento estuvo destinado a transformar la vida y el pensamiento del mundo occidental al que sin duda México culturalmente había ingresado. Berlin lo califica "como un cambio puntual ocurrido en la conciencia de occidente en el curso de los siglos XIX y XX" ( 2000: 20 ).

Ciertamente, el Romanticismo va de la mano con las revoluciones, con los grandes cambios sociales. Un contexto de ruptura era el ambiente propicio para su surgimiento o su adopción, y la Revolución de Independencia que trajo como consecuencia la invención de una nueva nación bautizada como México, representaba el divorcio con el mundo colonial y, al menos en teoría, con el lugar que habían tenido en él las culturas indígenas. Berlin dice también que el movimiento romántico "constituyó una protesta pasional contra cualquier tipo de universalidad" (2000: 27), lo que sin duda favorece que en cada nación tenga sus particularidades y que nosotros podamos hablar de un romanticismo "a la mexicana".

Nuestro romanticismo nace en el contexto del nacionalismo religioso mexicano. Cabe reflexionar al respecto a partir de la afirmación de David Brading acerca de que "la historia antigua de México empieza en mito y termina en profecía"(1988: 15) y a partir de la revisión de las teoría de Carlos de Sigüenza y Góngora (siglo XVII) quien defendió la tesis de que Quetzalcóatl era el apóstol Santo Tomás; de Motolinía, quien identificó al pueblo mexicano como el nuevo Israel (siglo XVI) y de Jerónimo de Mendieta para quien Hernán Cortés era el nuevo Moisés; así como de Fray Servando Teresa de Mier, el cual afirmó que fue el apóstol Santo Tomás quien imprimió la imagen de la Guadalupana en la tilma de Juan Diego (siglo XVIII). Con esa herencia, Morelos manifestó en Los sentimientos de la nación que María Santísima debía ser aclamada como "la patrona de nuestra libertad" y consideró a México como una república confesional (Alegría, 2004:158-160).

Ese nacionalismo, a decir del mismo Brading, se sustentó en los temas del patriotismo criollo, a saber: la consideración del imperio azteca como la gloria principal de la patria mexicana; por tanto, la revaloración del pasado indígena; el culto a la Guadalupana. Brading señala que "cuando la Insurgencia marchó bajo su estandarte, recibió la savia de la raíz central de la nacionalidad mexicana" (1988: 84); y el repudio a la conquista. Recordemos, no obstante, que está el otro tema señalado por Villoro: los criollos confiaban en la riqueza del territorio novohispano y pensaron que siendo independiente podría convertirse en la nación más rica del universo.

La feracidad de la tierra y más tarde los monumentos tanto prehispánicos como coloniales, serían parte importante de dicha riqueza y también símbolos que contribuyeran a la identidad entre 
la población variopinta que habitaba el vasto territorio que entonces tenía México. Por tal razón, los escritores de la época dedicaron muchos de sus textos a la exaltación del paisaje tanto natural como urbano.

- Voy a referirme ahora a aquellos textos en los que se pondera el paisaje, publicados en El año nuevo..., a ellos se dedica al menos uno en cada uno de los volúmenes de esta revista que apareció de 1837 a 1840.

\section{El paisaje, historia e identidad nacionales}

En la revista El año nuevo. Presente amistoso de 1837 hay un poema cuyo título es "El lago de Texcoco" escrito por Juan Nepomuceno Lacunza, referido al emblemático sitio donde, según la leyenda, los aztecas encontraron la señal que les había dado su dios Huitzilopochtli (un águila sobre un nopal devorando una serpiente) para identificar el lugar en el que debían establecerse. Antes de su desecación tratando de evitar las inundaciones que sufría la Ciudad de México, este era un lago de dos mil kilómetros (actualmente hay solamente diez que se han rehabilitado).

El poeta alude a dos cualidades del lago: sitio hermoso y apacible, tanto así, que le canta en estos términos:

Tú también en la tarde serena abres tu honda al amor y hermosura, y la luna suave, luz pura nos refleja en su frente feliz. [...] (El año nuevo..., 1838: 68)

De los elementos del patriotismo criollo, enfatiza Lacunza en este poema aquellos que se relacionan con la revaloración de lo indígena y con el consecuente repudio a La Conquista. Rememora de pronto una noche que fue aciaga para los españoles; pero no menos dolorosa para los indígenas, puesto que significó su venganza por la matanza en el Templo Mayor, orquestada por Pedro de Alvarado en ausencia de Hernán Cortés, quien fue a combatir a Pánfilo de Narváez. Alvarado se propuso llevar a cabo un ataque preventivo para evitar sublevaciones mientras los aztecas celebraban una ceremonia muy importante para ellos, por lo que estaban allí los más altos representantes de su sociedad. ${ }^{3}$ Se dice que hubo aproximadamente de trescientos a seiscientos muertos entre hombres, mujeres y niños.

En respuesta, los aztecas rodearon indignados el Palacio de Axayácatl, padre de Moctezuma, en el cual los españoles tenían prisionero a este último. Después de dos días de batallas en los que los extranjeros se veían perdidos ante el gran número de naturales que los atacaban, Cortés obligó al tlatoani a salir al

\footnotetext{
2- La ortografía de los textos tomados de El año nuevo... ha sido actualizada para este artículo

3- Según Francisco López de Gómara en esa fiesta, para cuya celebración los indígenas habían pedido permiso a Alvarado, quien lo concedió "Se juntaron más de seiscientos caballeros y principales personas, y hasta algunos señores, en el templo mayor; otros dicen que más de mil." Dice este cronista que al principio fueron a verlos bailar y "viéndolos tan ricos, se llenaron de codicia por el oro que llevaban encima, y así tomó las puertas, cada una con diez o doce españoles, y él entró dentro con más de cincuenta, y sin duelo ni piedad cristiana, los acuchilló y mató y quitó lo que llevaban encima. (s.f. : 236-237).
} 
- Revista de Ciencias Sociales y Humanidades. ISSN-P: 0188-9834 ISSN-E:2395-8669.

balcón para calmar a su pueblo; pero este recibió tres pedradas de la turba enardecida, a consecuencia de las cuales murió tres días después (algunos historiadores consideran que lo mataron los españoles), hecho que también querían vengar. ${ }^{4}$

Según López de Gómara, luego de la muerte de Moctezuma, Cortés intentó hacer las paces con los indígenas, pero estos lucharon con denuedo durante dos días, con la consecuente pérdida de vidas, más del lado de los nativos porque, de acuerdo con los cronistas, eran miles ${ }^{5}$; pero los españoles también salieron muy disminuidos.

Estos quemaron muchas casas e inhabilitaron ocho puentes, según reporta López Gómara. Antes de emprender la huida acompañados por los tlaxcaltecas, sus aliados, Cortés ordenó a su camarero que abriera la sala donde se encontraban el oro, la plata, las joyas, las piedras preciosas y las mantas ricas; tanto él como sus hombres cargaron con todo lo que pudieron y el peso de ese cargamento contribuyó a su derrota aquella noche en la que fueron alcanzados por los aztecas que llegaron en canoas por el lago. Allí quedaron sepultados cientos de españoles y tlaxcaltecas, junto con decenas de caballos y yeguas, y el noventa por ciento del tesoro de Axayácatl. Así expresa el poeta su pesar por tal episodio:

Mas ¡Oh Dios! ¡Qué memoria! Cesa el canto

en mi trémulo labio,

y de mis ojos el amargo llanto

siento correr, joh patria, oh patria mía!

Tus últimos guerreros,

tu esperanza postrera,

hallaron tumba fría

en ti ¡oh lago!... finaron su carrera

¡Cuánto no cubren tus salobres ondas

del miserable indiano

el cadáver sangriento y el tesoro,

sus joyas y su oro

a ti arrojadas por su propia mano.

(El año пuevo..., 1837: 68)

4- López de Gómara lo registra así: "Cargaban tanto y porfiaban en entrar en la casa, que rogó Cortés a Moctezuma se subiese a una azotea y mandase a los suyos cesar e

irse. Subió, se puso al pretil para hablarlos, y nada más empezar, tiraron tantas piedras desde abajo y desde las casas fronterizas que de una que le acertó en las sienes le derribaron y mataron sus propios vasallos [...] Después, Cortés publicó la herida y peligro de Moctezuma, mas unos lo creían y otros no, todos peleaban a porfía. Tres días estuvo Moctezuma con dolor de cabeza y al cabo murió. (s.f. : 241). En su segunda carta al rey de España Cortés de dice: "Y el dicho Mutezuma, que todavía estaba preso, y un hijo suyo con otros muchos señores que principio se habían tomado, dijo que le sacasen a las azoteas de la fortaleza y que él hablaría a los capitanes de aquella gente y les haría que cesase la guerra. Y yo le hice sacar y en llegando a un pretil fuera de la fortaleza, queriendo hablar a la gente que por allí combatía, le dieron una pedrada los suyos es la cabeza, tan grande, que de allí a tres días murió." (1971: 79).

5- Tan solo en la azotea de una torre que estaba cerca del fuerte de los españoles, murieron quinientos naturales, según reporta López Gómara: “Pelearon tres horas allá arriba, pues, como eran muchos los indios, ni los podían vencer, ni acabar de matar. Al fin murieron los quinientos indios como valientes hombres. Y si hubiesen tenido armas iguales más mataran que murieran, según lugar y corazón tenían” (244). 
El sujeto lírico se despide diciendo.

La tempestad que amenaza

turbará menos mi calma

que los recuerdos que en mi alma

tú has venido a despertar.

(El ã̃o nuevo..., 1837: 69)

Lo que se observa en este poema es la expresión del sentimiento patriótico y la exaltación del pasado indígena de la mano con el repudio a la Conquista. Al final y a tono con el carácter romántico del texto, el poeta le solicita al lago:
¡Ah! No turbes el gozo sincero
que se mira en la faz de las bellas,
y respeta el encanto que en ellas
nos convida a tu orilla a venir.
(El año nuevo..., 1837: 68)

En el número correspondiente a 1838 de esa misma revista, Manuel Tossiat Ferrer publicó un poema dedicado a un elemento del paisaje urbano que sigue siendo emblemático en la Ciudad de México: la Alameda Central, creada en el siglo XVI por el virrey Luis de Velasco y que desde entonces ha sido uno de los lugares de esparcimiento más entrañables para los habitantes de esta urbe. Su título es: "A la alameda" a la que el poeta expresa un saludo homérico:

¡Salve sitio delicioso,
donde todo es hermosura,
do reina delicia pura,
y es eternal el reposo!
(El año nuevo..., 1838: 205)

Ubica el sujeto lírico en este canto a las jóvenes "hermosas" que hacen "con grupos de rosas/ su peinado pastoril", a los pajarillos que beben en las fuentes "donde reflejan su brillo/del sol los rayos ardientes." (1838:206) Se refiere también al movimiento de las ramas de los árboles en ese vergel, y dice : "mas el viento cruel/ pronto las flores marchita" (El año nuevo... ,1838: 206). Entonces aprovecha para hacer una reflexión filosófica:

Tal del hombre es la existencia:

nace, lo adorna el candor,

y cual la temprana flor

se marchita su inocencia.

(El año nuevo..., 1838: 206) 
- Revista de Ciencias Sociales y Humanidades. ISSN-P: 0188-9834 ISSN-E:2395-8669.

Vincula Tossiat Ferrer ese sitio ubicado en el centro de la ciudad, con los acontecimientos históricos referentes sin duda a las batallas que se libraron en aquella centuria debido a las invasiones extranjeras (española con Barradas, 1829; francesa 1838-39) ${ }^{6}$ y al choque de facciones internas. En esa primera mitad del siglo XIX el país vivió una primera presidencia (la de Guadalupe Victoria), que terminó en la anarquía; luego siguió la anulación de la elección de Gómez Pedraza y la presidencia, muy accidentada, de Vicente Guerrero. De 1836 a 1841, hubo siete presidentes, entre los que estuvo el primero de sus once periodos, Antonio López de Santa Anna. Se vivió también la guerra de Independencia de Texas. Seguramente a ese contexto se refiere el poema en las siguientes estrofas:

\author{
Mas tanta felicidad \\ bosque amado ¿siempre viste? \\ ¿o un día teatro fuiste \\ de funesta adversidad? \\ Sí, que fuerza irresistible \\ en la guerra destructora, \\ lanzó bala silbadora \\ rompiendo el aire apacible. \\ Mas ya de tu aura serena \\ no perturbará el reposo, \\ ni el homicida alevoso, \\ ni el bronce que ardiente truena.
}

Ya no estremece este suelo

el instrumento de muerte:

ni con la sangre del fuerte

se tiñe el manso arroyuelo.

(El año nuevo..., 1838: 207)

\footnotetext{
6- El intento de reconquista del español Isidro Barradas tuvo lugar unos meses después de que Vicente Guerrero tomara el poder. El 5 de julio de 1829 se hacía a la mar la expedición de once embarcaciones con 3.376 hombres. Arribaron a las costas de Tampico y fueron repelidos inicialmente por el general Felipe de la Garza y posteriormente por Antonio López de Santa Anna. La falta de apoyo de parte de la Corona, el no encontrar aquel del interior con el que contaban y el debilitamiento de sus tropas, cuyos integrantes se contagiaron de fiebre amarilla, pusieron en difícil situación a los españoles y, finalmente, del asaltó de Santa Anna a su fuerte el 10 de septiembre, como consecuencia del cual murieron 9 oficiales y 134 soldados, llevó a la capitulación de Barradas, quien se fue a Nueva Orleans. (Ruiz de Gordejuelas, 2011).

Del 16 de abril de 1838 al 9 de marzo de 1839, tuvo lugar la conocida como Guerra de los Pasteles, que fue pretexto para la primera intervención francesa en México. Para justificar esta invasión, se habían presentado constantes reclamaciones de los Ministros plenipotenciarios franceses. El Barón Deffaudis exigía una suma considerable que uno de sus conciudadanos reclamaba por algunos pasteles que le habían robado varios soldados. Para apoyar las reclamaciones el ministro francés presentó un ultimátum, con solicitudes fuera de lugar, entre ellas conceder libertad de comercio a los pequeños empresarios franceses. Ante la negativa del gobierno mexicano, una cuadrilla francesa presentó un bloqueo que duró ocho meses. El 27 de noviembre, tras un ataque al Castillo de San Juan de Ulúa, hubo un pacto entre las fuerzas mexicanas y francesas; pero el 5 de diciembre los franceses atacaron por sorpresa la plaza de Veracruz; pero fueron derrotados por Antonio López de Santa Anna, quien perdió "un pie por una herida de fusil. (De Arrangoiz, 1985: 374-375).
} 
Finalmente, recuerda el poeta sus experiencias de infancia en la alameda y le brinda una alabanza para cerrar:

¡Salve, bosque encantador!

tú la dulce estancia eres

donde reinan los placeres,

donde preside el amor.

(El año nuevo..., 1838: 203-208)

En el tomo IV de El año nuevo... (1839), aparece un texto de José María Tornel por entonces Ministro de Guerra en el gobierno de Antonio López de Santa Anna. Dicho artículo está dedicado al Pico de Orizaba, ciudad en la que este escritor, hombre de armas y político, había nacido, en el Estado de Veracruz.

Menciona el autor la altura de ese coloso (17 mil pies sobre el nivel del mar) y la forma en que lo llamaron los antiguos mexicanos: Citlaltepetl (monte de la estrella) o Poyantecatl (gigante que arroja humo).

Su relato se relaciona con la alegría que le da ver ese volcán, cuando lo divisa desde un frágil barco en el cual regresaba de los Estados Unidos y que fue azotado por una tormenta que duró catorce días. Exalta ese pico que se hallaba entre algunas nubes que "le servían de cabellera o de corona de oro" (El año nuevo... ,1839: 75) y aprovecha para mencionar también algunos otros valiosos elementos naturales y urbanos de su estado natal: el alto Naucantepetl, la sierra de San Martín y "la ciudad de Veracruz con sus cúpulas y torres" (El año nuevo..., 1839: 75). Aquí la mención del paisaje se hermana literalmente con el sentimiento patriótico:

¿Quién dirá lo que todo hombre siente al volver a su patria adorada, después de una larga y penosa ausencia? ¿Podrá un corazón que no sea mexicano gozar de todo el purísimo deleite que causan estas incomparables y magníficas escenas? Otros conocerán el placer de admirar lo grande y lo bello, pero el mexicano experimenta además el noble y generoso orgullo de ver y poseer una patria espléndida por sus montañas, fértil en su virgen suelo, deliciosa en su clima, rica en plata, perlas y oro, dueña, en fin, de cuantos bienes el universo envidia.(El año nuevo..., 1839: 75)

Recupera también Tornel en este texto la revaloración de la cultura indígena. Sigue diciendo:

Los aztecas en sus confusos anales mencionan las erupciones periódicas del Orizaba en los siguientes términos: En este año el monte de la estrella ha humeado. Citlalcholoha lo nombraron, como opina el erudito barón Humbolt, porque se halla al E. de la ciudad de Cholula: lo confundieron así mismo con la estrella de la mañana, con el Tlazolteotl de los astrónomos mexicanos.(El año nuevo... ,1839:76)

Lamenta que no le haya tocado presenciar la primera erupción de ese volcán, y remite a la cultura occidental al mencionar que de haberlo hecho hubiera sido "menos audaz que Plinio; pero no menos apasionado al examinar y contemplar esos cuadros de horror sublime" (El año nuevo... , 1839: 77), en clara referencia al naturalista romano conocido como Plinio el viejo, quien quiso contemplar tan de cerca 
la erupción del Vesubio que sepultó Pompeya y Herculano, que murió, se cree que asfixiado. Hay otro elemento de la cultura europea presente en el texto de Tornel: la poética de la sublimidad iniciada con Dionisio Casio Longino en el siglo III d. C. ${ }^{7}$

Longino se refiere a cinco fuentes de la sublimidad: cierta elevación del espíritu que nos hace pensar felizmente las cosas, lo patético, las figuras tanto de pensamiento como de dicción manejadas o giradas en cierto modo, la nobleza de la expresión en cuanto a la elección de las palabras, así como a su composición y colocación con toda magnificencia y dignidad. Asegura que no hay cosa que más realce un discurso que una pasión excitada a propósito.

Tornel realmente fuerza su texto para introducir algunos elementos de esta poética, describiendo una erupción que no vio:

Menos audaz que Plinio, pero no menos apasionado que él a examinar y contemplar esos cuadros de horror sublime, hubiera yo visto la faz turbada del sol, un tiempo que no era ni día ni noche, ríos de lava encendida abriéndose paso, empujando y derritiendo peñascos de nieve, de pórfido, de basalto y de granito; la horrenda detonación hubiera sonado a mis oídos como el último gemido de la naturaleza moribunda ¡temblara yo miserable criatura! Temblaron las selvas y los montes, los valles y las colinas; temblaron los pueblos y las ciudades. La memoria de ese suceso se ha perdido en la noche de los tiempos, consérvanse empero rastros inextinguibles de su existencia. (El año nuevo... , 1839 :77)

Después de esa digresión, el autor vuelve a la exaltación del Pico de Orizaba como una maravilla natural de su patria:

El volcán es hoy pompa y gala de su comarca. Las ciudades de Orizaba, Córdoba, Chalchicomula, el antiguo Pinhuitzapan, Huatuzco y cien pueblos más reciben su benigna influencia: sus aguas limpias, delgadas y frescas fertilizan los campos; todo ser que allí vive, respira su oxígeno purísimo. Al nacer y al ponerse el sol, se multiplican los encantos y prodigios de la montaña; brilla entonces en él el esplendor del oro, y viste la púrpura de la aurora y del crepúsculo vespertino. (El año nuevo... , 1839: 77)

\footnotetext{
7- Pilar García, Académica del Departamento de Literatura de la Universidad de Chile, advierte sobre la cuestionada autoría de Casio Longino en referencia a "La traducción revisada y anotada del tratado De lo sublime a cargo de Pablo Oyarzún y Eduardo Molina [que] anuncia y propone el rescate de las dimensiones estéticas, filosóficas y literarias de este manuscrito que data del siglo I d. C." Tal traducción fue publicada con el título De lo sublime y se hace referencia al autor como Pseudo-Longino cito un largo párrafo de García que resume la explicación acerca de la puesta en duda de la autoría de Casio Longino:

La atribución del tratado a Casio Longino, orador del siglo III d.C, hecha en la primera publicación del texto en 1554 se mantuvo durante los siglos XVII y XVIII, momentos de mayor influencia del escrito, que fuera considerado fundamento de la estética y la crítica literaria junto con la Poética de Aristóteles y el Arte poética de Horacio. Un nuevo acercamiento filológico al texto a comienzos del siglo XVIII revela la incertidumbre respecto a la autoría de Dionisio «0» Longino, tras lo cual se sumaría la eventual autoría de Dionisio de Halicarnaso. Para Oyarzún atribuir la autoría del tratado a Dionisio de Halicarnaso o a Casio Longino no sería plausible por las diferencias de asunto y estilo entre el tratado y las obras conocidas de estos autores. Por este motivo lo denomina «Pseudo» Longino, o «Anónimo». Por otro lado, remontar la fecha de producción del texto al siglo I d.C, bajo el imperio de Caligula, resulta pertinente tomando en cuenta la discusión en torno a la decadencia de la oratoria (siglos I y II d.C.) presente en el capítulo XLIV del tratado, y común a Séneca, Petronio, Tácito y Quintiliano (García, 2088)
} 
El elemento religioso propio del nacionalismo mexicano también está presente en el texto de Tornel, de la mano con la fuerza de la naturaleza. Así lo cierra:

Pasan algunos siglos y dejan de existir las obras estupendas de Artemisa y Semiramis. La justicia del destino convierte en polvo los esfuerzos del genio que busca en vano los secretos de la inmortalidad. Pirámides, obeliscos, teocalis desaparecerán de las regiones de Egipto y México, y el Orizaba existirá: las montañas colosales no obedecen más que a Dios.(El año nuevo..., 1839: 78)

Por último, en el tomo IV, de 1840, se publicó el considerado por Marcelino Menéndez y Pelayo como mejor poema del primer romanticismo mexicano: "Profecía de Guatimoc". La mayor parte de este alude a la conversación que Cuauhtémoc sostuvo con el sujeto lírico, a través de la cual y al más puro estilo sublime, el tlatoani profetiza; entre otras cosas, la muerte temprana del autor, Ignacio Rodríguez Galván fuera de la patria, de la que salía por primera vez. Advierte también sobre la llegada de un invasor "más bárbaro y cruel que el español" que vendría del norte. Esa conversación tiene lugar en otro de los sitios emblemáticos de la Ciudad de México, un refugio natural en medio del caos en que hoy se vive en ella: el cerro de Chapultepec. Topónimo que viene del náhuatl chapul (in) saltamontes, y tepe (tl) cerro o montaña.

En este cerro Moctezuma Ilhuicamina (1440-1469), mandó construir el acueducto para conducir el agua desde Chapultepec hasta México-Tenochtitlán. El responsable de dicha obra fue Nezahualcóyotl, señor de Texcoco, quien obtuvo como pago habitar en Chapultepec. Según las crónicas a él se debió la siembra y cuidado de los más longevos ahuehuetes. El sitio se transformó en el lugar donde habitaban los dioses del agua. Hernán Cortés hizo talar los árboles más cercanos a los manantiales para que no los contaminaran con sus hojas, lo que disminuyó la espesura del bosque.

En el periodo virreinal, sobre los cimientos de lo que fuera la residencia de Moctezuma, se construyó el palacio que dio cobijo a varios virreyes, así como a visitantes distinguidos.

La explosión de un polvorín en el siglo XVIII, cuyo resultado fue la destrucción del edificio, llevó a que el nuevo palacio se construyera en la cima del cerro, donde antiguamente había estado una ermita dedicada a San Miguel Arcángel. Era el mes de agosto de 1785 y gobernaba Nueva España el virrey Bernardo de Gálvez. Luego de su muerte sin ver concluida la obra, en 1786, esta se suspendió y en 1792 el virrey Juan Vicente de Güemes Pacheco y Padilla, segundo conde de Revillagigedo, destinó el edificio a Archivo General del Reino de Nueva España, proyecto que, finalmente, tampoco pudo concretarse.

Alexander von Humbolt, quien visitó el sitio en 1803, denunció en su obra Ensayo político del Reino de Nueva España, el vandalismo de los ministros de la Real Hacienda, quienes estaban vendiendo vidrios, puertas y ventanas del edificio.

El Ayuntamiento de la Ciudad de México lo adquirió en 1806. Estuvo abandonado por muchos años, hasta que en 1833, por decreto, se convirtió en sede del Colegio Militar. Fue a partir de esa fecha cuando se le empezó a llamar "castillo".

Su funcionamiento como colegio empezó hasta 1844, luego de que se le hiciera varias adaptaciones. En 1847 (12 y 13 de septiembre), el lugar fue bombardeado por el ejército estadounidense y, después de arreglar los destrozos, en 1849 fue devuelto al Colegio Militar. Como es sabido, Maximiliano y Carlota 
decidieron establecer allí su residencia imperial (1864). A partir de la caída del Imperio (1867) el edificio quedó abandonado, hasta 1872.

En 1876 se decretó el establecimiento del Observatorio Astronómico, Meteorológico y Magnético en dicho espacio. Fue inaugurado dos años más tarde y solo funcionó como tal hasta 1883, cuando se decidió el regreso del Colegio Militar y la adaptación del edificio como residencia de gobierno. El presidente Manuel González ordenó varias modificaciones arquitectónicas y a lo largo del gobierno de Porfirio Díaz, castillo y alcázar alcanzarían un gran esplendor.

Lo habitaron después varios mandatarios surgidos del proceso revolucionario: Francisco I. Madero, Venustiano Carranza, Álvaro Obregón, Plutarco Elías Calles, Emilio Portes Gil, Pascual Ortiz Rubio y Abelardo Rodríguez.

Fue Lázaro Cárdenas quien, el 3 de febrero de 1939, expidió la Ley Orgánica en virtud de la cual el edificio se convirtió en Instituto Nacional de Antropología e Historia. Esa misma ley lo señalaba parte del patrimonio nacional para que como Museo Nacional de Historia (inaugurado el 27 de septiembre de 1944) abrigara todas las colecciones del Departamento de Historia del antiguo Museo Nacional de Arqueología, Historia y Etnografía ( www.mnh.inah.gob.mx/historia/hist_historicos.html).

El análisis del mencionado poema de Rodríguez Galván, editor de los órganos en que publicaron los escritores de la Academia de Letrán, es motivo del libro Historia y religión en Profecía de Guatimoc. Símbolos y representaciones culturales (Alegría, 2004).

El poeta invoca a los reyes que dominaron el Anáhuac justo en Chapultepec, entonces, a la manera bíblica, la tierra tiembla y una mano cadavérica atrapa la suya. Es Cuauhtémoc que respondió a la invocación. Allí empieza el diálogo. Me limitaré a citar la estrofa de referencia con la cual da inicio al poema:

Tras negros nubarrones se asomaba pálido rostro de luciente luna, tristemente blanqueando los peñascos que de Chapultepec la falda visten. Cenicientos a trechos, amarillos, o cubiertos de musgo verdinegro a trechos se miraban; y la vista de los lugares de profundas sombras con terror y respeto se apartaba. Los corpulentos árboles ancianos, en cuya frente siglos mil reposan, sus canas venerables conmovían del viento leve al delicado soplo, o al aleteo nocturno del cuervo, que tal vez descendiendo en vuelo rápido rizaba con sus alas sacudidas las cristalinas aguas de la alberca, en donde se mecía blandamente la imagen de las nubes retratadas 
en su luciente espejo. Las llanuras

y las lejanas lomas repetían

el aullido siniestro de los lobos,

o el balar lastimoso del cordero,

o del toro el bramido prolongado.

(El año nuevo..., 1840: 60-61)

Esta larga cita de la estrofa inicial del poema permite observar una de las características de la poética de la sublimidad, misma de la que Rodríguez Galván tuvo conocimiento porque la imprenta de su tío, Antonio Galván Rivera publicó en 1834 las Lecciones de retórica y poética de Hugo Blair, volumen aumentado con el Tratado de la sublimidad del ya mencionado Dioniso Casio Longino. De las cinco fuentes de la sublimidad vemos en este principio del poema lo patético, en cuanto a que el poeta ubica al receptor en un ambiente sombrío, mismo en el que sostendrá un diálogo con Cuauhtémoc que resulta realmente profético.

Remito al libro de mi autoría ya mencionado donde analizo todos los elementos de la poética de la sublimidad que se pueden distinguir en el poema, aquí me interesa destacar que en él están presentes temas como la revaloración del pasado indígena, y el repudio a la Conquista; a la de antes y a la de ahora, misma que profetiza. Al erigir en él a Cuauhtémoc como héroe nacional y darle la voz de profeta, Rodríguez Galván participa del nacionalismo religioso mexicano que jugó, un importante papel en el México recién independizado. El paisaje no podía ser más emblemático: el cerro de Chapultepec. Un lugar que se eleva hacia lo divino, pero mantiene contacto con lo terreno, lugar desde donde el sujeto lírico espera "rasgar el velo de futuros tiempos", Este es, desde mi punto de vista, el mejor poema publicado en El año nuevo...

\section{Conclusión}

La presencia del paisaje en la mayoría de las publicaciones periódicas decimonónicas es una constante. La intención de los escritores por despertar un sentimiento de identidad en la población de aquel México que apenas iniciaba su vida independiente también es clara, manifestación de su consciencia política y su respuesta cultural ante el mundo cambiante en el que les tocó vivir.

Evidentemente, la etapa de construcción nacional por la que se transitaba era el ambiente propicio para destacar el paisaje en la literatura, porque los nacionalismos son ciertamente movimientos sociopolíticos que surgen en un determinado territorio y en un periodo histórico específico. "El territorio nacional se convierte, por lo tanto, en algo más que una simple área geográfica más o menos delimitada. Se convierte en un territorio 'histórico', único y distintivo, con una identidad ligada a la memoria y una memoria encadenada a la tierra” (Nogué, 2005: 148).

Era inevitable que los miembros de una academia, la de San Juan de Letrán, que en el siglo XIX se propuso mexicanizar la literatura, exaltaran las bondades del territorio nacional y destacaran las cualidades de paisajes ligados a su historia y a su belleza natural, con la intención consciente de contribuir a la construcción de la identidad mexicana durante los primeros años de independencia. 


\section{Referencias}

Alegría de la Colina, Margarita. 2004. Historia y religión en Profecía de Guatimoc. Símbolos y representaciones culturales. México: Universidad Autónoma Metropolitana. División de Ciencias Sociales y Humanidades.

Auerbach, Erich. 1950. Mimesis. La representación de la realidad en la literatura occidental. México: Fondo de Cultura Económica.

Berlin, Isaiah. 2000. Las raíces del romanticismo. Madrid: Grupo Santillana.

Brading, David. 1988. Mito y profecía en la historia de México. México: Fondo de Cultura Económica. Cortés, Hernán .1971. Cartas de relación. México: Editorial Porrúa.

De Arrangoiz, Francisco de Paula. 1885. México desde 1808 hasta 1867. México: Editorial Porrúa.

García, Pilar. 2008. Pseudo-Longino. De lo sublime. Arthesis, 44. DOI: http://doi.org/10.4067/S071871812008000100012

Instituto Nacional de Antropología e Historia. Antecedentes históricos del Castillo de Chapultepec. http://www.inah.gob.mx/red-de-museos/295-museo-nacional-de-historia-castillo-de-chapultepec (15 de abril de 2018).

Kohut, Karl. 2008. Clavijero y las disputas sobre el nuevo mundo en Europa y América. Destiempos, 3 (14): 52-81.

López de Gómara, Francisco. 1552. La conquista de México. México: APP Editorial

Maderuelo, Javier. 2005. El Paisaje. Génesis de un concepto. Madrid: Abada editores.

Miranda, Celia. 1985. La novela corta en el primer romanticismo mexicano. México: Universidad Nacional Autónoma de México.

Nogué, Joan. 2005. Nacionalismo, territorio y paisaje en Cataluña, compilado por Nicolás Ortega. México: Ediciones UAM. Fundación Duque de Soria, 148-169.

Ortega Cantera, Nicolás (ed.). 2005. Paisaje, memoria histórica e identidad nacional. Madrid: Ediciones UAM, Fundación Duque de Soria.

Pascual Gay, Juan .2009. Paisajes y géneros literarios. Ensayos de geografía literaria. San Luis Potosí: El Colegio de San Luis.

Perales, Alicia. 2000. Las asociaciones literarias mexicanas. Tomos I y II. México: Universidad Nacional Autónoma de México.

Rosas, Patricia. 2012. Las sociedades científicas en México. Eutopia. Revista del colegio de ciencias y humanidades para el bachillerato, 5:18-24.

Ruiz de Gordejuelas, Jesús. 2011. Barradas: El último conquistador español. La invasión a México de 1829. México: Instituto Nacional de Estudios Históricos de las Revoluciones de México.

El año nuevo. Presente amistoso t. I. 1837. Edición facsimilar. 1966. México: Universidad Nacional Autónoma de México (Ida y regreso al siglo XIX).

El año nuevo. Presente amistoso t. II. 1838. Edición facsimilar. 1994. México: Universidad Nacional Autónoma de México (Ida y regreso al siglo XIX).

El año nuevo. Presente amistoso t. III. 1839. Edición facsimilar. 1994. México: Universidad Nacional Autónoma de México (Ida y regreso al siglo XIX). 
- Revista de Ciencias Sociales y Humanidades. ISSN-P: 0188-9834 ISSN-E:2395-8669.

El año nuevo. Presente amistoso t. IV. 1840. Edición facsimilar. 1994. México: Universidad Nacional Autónoma de México (Ida y regreso al siglo XIX).

Villoro, Luis. 1999. El proceso ideológico de la Revolución de Independencia. México: Consejo Nacional para la Cultura y las Artes.

Zoido, Florencio. 2012. El paisaje. Un concepto útil para relacionar estética, ética y política. Scripta Nova. Revista Electrónica de Geografía y Ciencias Sociales.16 (407).

Vázquez, Josefina. 2001. Gran historia de México ilustrada, t. III, El nacimiento de México, 1750-1856. De las reformas Borbónicas a la Reforma. México: Planeta/Consejo Nacional para la Cultura y las Artes/ Instituto Nacional de Antropología e Historia. 